\title{
A latent profile analysis of the link between sociocultural factors and health-related risk- taking among U.S. adults
}

\author{
Jessica K. Perrotte ${ }^{1 *}$, Eric C. Shattuck ${ }^{2,3}$, Colton L. Daniels ${ }^{2,4}$, Xiaohe $X u^{4,5}$ and Thankam Sunil ${ }^{3}$
}

\begin{abstract}
Background: Research suggests that health/safety behaviors (e.g., drinking heavily) and medical behaviors (e.g., donating blood) may be perceived as inherently risky, and further suggests there is substantial variation in the likelihood of engaging in a particular health-related risk behavior across people. Research examining demographic and sociocultural factors related to both health/safety and medical risk-taking is highly limited. Importantly, with very few exceptions the literature examining health risks characterized by potentially hazardous health behaviors (e.g, heavy alcohol use, driving without a seatbelt) is kept separate from the literature examining health risks characterized by potentially beneficial medical behaviors (e.g., donating blood, taking medication). In the interest of health promotion, it is critical for researchers to identify - and describe - individuals who are less inclined to engage in health-harming behaviors while at the same time being more inclined to engage in health-benefiting behaviors. Identifying such a subtype of individuals was the guiding aim for this study.
\end{abstract}

Method: A national sample of adults in the United States responded to a survey on sociocultural and demographic correlates of health behaviors. Health-related risk-taking indicators were measured using the items from the health/ safety and medical subscales of the DOSPERT-M. Subtypes of risk-takers were identified using latent profile analysis (LPA). Follow-up analyses to describe subtype demographic characteristics were conducted.

Results: LPA identified four subtypes of risk-takers, including a subtype ( $n=565,45 \%$ of the sample; labeled "divergent") that was comprised of individuals who highly endorsed medical risk-taking (e.g., taking medicine, giving blood) and minimally endorsed health/safety risk-taking (e.g., drinking heavily, unprotected sex). Subsequent analyses suggested that, among other findings, divergent profile members were likely to be married, endorse familial interdependence, and orient toward masculinity rather than femininity.

Conclusion: By examining potentially modifiable factors related to individuals' inclinations to engage in health protective behaviors, this study is an important step toward improving current health behavior interventions among U.S. adults.

Keywords: Health risk, Medical risk, Health behaviors, Gender, Gender role, Individualism, Collectivism, Familism, Locus of control

\footnotetext{
* Correspondence: j.perrotte@txstate.edu

'Department of Psychology, Texas State University, UAC 253, 601 University

Drive, San Marcos, TX 78666, USA

Full list of author information is available at the end of the article
}

(c) The Author(s). 2021 Open Access This article is licensed under a Creative Commons Attribution 4.0 International License, which permits use, sharing, adaptation, distribution and reproduction in any medium or format, as long as you give appropriate credit to the original author(s) and the source, provide a link to the Creative Commons licence, and indicate if changes were made. The images or other third party material in this article are included in the article's Creative Commons licence, unless indicated otherwise in a credit line to the material. If material is not included in the article's Creative Commons licence and your intended use is not permitted by statutory regulation or exceeds the permitted use, you will need to obtain permission directly from the copyright holder. To view a copy of this licence, visit http://creativecommons.org/licenses/by/4.0/ The Creative Commons Public Domain Dedication waiver (http://creativecommons.org/publicdomain/zero/1.0/) applies to the data made available in this article, unless otherwise stated in a credit line to the data. 
Multiple possible outcomes are associated with any given health behavior and this inherent uncertainty surrounding the outcomes defines the behavior as risky [1]. For example, heavy drinking at a company party can lead to subjectively positive (e.g., feeling more at ease) or negative (e.g., behaving recklessly) consequences. Wellknown risky behaviors (e.g., substance use, unprotected sex) can lead to negative impacts on morbidity and mortality $[2,3]$, but the risks of health behaviors involving medical procedures (e.g., taking medication, surgery) are less studied, although medical-related behaviors can have both positive and negative consequences. For instance, taking medication could lead to symptomatic relief or potential adverse effects [4].

Research indicates risk-taking propensity is influenced by the extent of the knowledge of all possible outcomes and by how much each outcome is valued by the risktaker [1]. Importantly, individual characteristics also shape risk-taking [1]. For example, educational attainment may affect knowledge about potential outcomes due to variation in exposure to relevant information. Similarly, differences in the endorsement of numerous sociocultural values may influence risk-taking. For instance, collectivistic individuals [5] may shy away from socially discouraged behaviors (e.g., drinking heavily [6]) while also being more likely to engage in health-related risk-taking that benefits others (e.g., donating blood). The role of sociocultural factors in health-related risktaking is understudied, particularly regarding medical risk-taking. As suggested by Weber and Johnson [7], uncovering the factors that contribute to health-related risk-taking will better inform health interventions.

Risk-taking is linked with multiple individual-level factors. For instance, longitudinal research indicates that age is related to health/safety risk-taking, with older individuals generally taking fewer risks [8]. Education is also linked to health-related risk-taking [9], perhaps due to better knowledge of the potential outcomes [7]. Research also suggests women report less risk-taking than men across many health behaviors [8]. For one, women are less likely to receive a flu vaccine [10], but on the other hand engage in more preventive medical care than men [11]. In addition, research suggests women are more likely than men to seek health-related information [12] and thus may be more inclined to educate themselves about the costs and benefits of medications, medical procedures, and so on. Studies typically examine gender in relation to health attitudes and behaviors using a dichotomous (i.e., male/female) variable; however some theories of gender suggest that it is beneficial to consider the degree to which individuals endorse gender-related traits that are considered masculine or feminine, which may be inconsistent with their identifications as male, female, or another gender [13]. Research examining the link between gender role orientation - rather than dichotomous gender identifications - and health-related risk-taking propensity across an array of health indicators is scarce, however.

Research suggests that, although genetic factors account for much of the variance across domains of risktaking, decisions to engage in risk behavior are also shaped by environmental factors [14]. Because of this, researchers recognize the need for more work examining potential sources that contribute to risk-taking propensity within specific domains [8]. To meet this need, the present study examines the role of several sociocultural factors with theoretical relevance to health behaviors.

\section{Sociocultural factors and health-related risk- taking}

Norms transmitted through the sociocultural environment shape individual values [15]. These values then inform perceptions of - and engagement in - risky behavior [16]. However, literature examining the concurrent and incremental relations of relevant sociocultural values with risk-taking across health-related domains is scattered and scarce.

Some values that have received attention in the health literature are individualism and collectivism [5]. Broadly, individualistic-oriented people value independence and prioritize fulfilment of personal needs and goals. Conversely, collectivistic-oriented people value connection with others and may place others' needs and goals above their own. Some research suggests collectivism is protective against several health/safety risk behaviors that may be socially discouraged by family and friends [6]. The same study found one positive relation between individualism and hazardous alcohol use [6].

Research on individualism and collectivism in medical risk-taking is limited. One study found a positive link between collectivism and perceived vulnerability to disease [17], indicating that people higher in collectivism may engage in medical behaviors that prevent disease or minimize its effects, perhaps so they do not burden close others. Additionally, some medical risks (e.g., blood donation) are predominantly altruistic in nature. In support of this, research from India - where collectivism is reputedly a dominant cultural value [18] - found that people are motivated to donate blood by a sense of community obligation [19].

Relatedly, some people value and are motivated by familial connections (i.e., familism) [20]. Although extant literature typically characterizes familism as a Hispanic cultural value, research suggests the construct can be applied across diverse ethnoracial groups [21]. There is little research examining the role of familism in healthrelated risk-taking among adults, aside from studies that examine familism in relation to alcohol and substance 
use, often finding an inverse link [22]. Because of the similarity between familism and collectivism [23], it is possible they may map onto health-related risk-taking similarly, with some exceptions. As with collectivism, familism may motivate individuals to engage in beneficial behaviors in order to preserve their own health and safety for the sake of their family. However, familism may relate to engagement in altruistic behaviors (e.g., blood donation) only when it directly benefits a family member. Because of the potential overlap between collectivism and familism on health-related risk-taking, it is important for research to disentangle their unique effects by including both factors within the same model.

Finally, health-related risk-taking may be shaped by one's perceived control over their own health. Data suggest that $89 \%$ of the U.S. population believe in a God or God-like entity [24]. Many people believe that God is ultimately responsible for their health [25], a belief often referred to as the God Locus of Health Control (GLHC [26]). Research suggests increased GLHC may be linked to poor health behaviors (e.g., reduced vegetable consumption [27]). As with the constructs noted earlier, research examining GLHC and risk-taking across health domains is scarce. Given the theoretical relevance of each of these constructs, an investigation of their concurrent relations to health-related risk-taking is warranted.

\section{Current study}

Studies examining how demographic and sociocultural values relate to both health/ safety related risktaking (e.g., alcohol use, driving without a seatbelt) and medical-related risk-taking (e.g., donating blood, taking medication) within the same model are scarce. Risk-taking theorists posit that there are distinct psychological processes that are involved during risky decision making [1]. The thought processes underlying some risky decisions are characterized as either "hot" (i.e., affective) or "cold" (i.e., deliberate) [1]. However, the propensity, or inclination to engage in the health-related risk behavior may be further understood when contextualized within sociocultural perspectives and worldviews [28]. Researchers have noted the importance of accounting for demographic factors alongside sociocultural factors when examining health-related risk-behaviors (e.g., receiving a vaccine), so that groups of individuals who may be more or less likely to engage in specific health behaviors may be identified [28]. With this in mind, implementing a person-centered statistical approach (i.e., latent profile analysis; LPA), so that subtypes of such individuals may be identified, would also be beneficial. A previous study used a similar person- centered approach (i.e., Latent Class Analysis; LCA) to examine typologies of health behaviors (e.g., cigarette and alcohol use, vaccines and other routine medical care) among U.S. adults, and examined how four demographic factors (i.e., race/ethnicity, sex, region, and age) related to membership in each subtype [29]. Indeed, subtypes of individuals emerged during analysis that the researchers labeled "health promoting" (i.e., engaging in more healthy behaviors and fewer unhealthy behaviors) while other individuals were identified as "health compromising." [29] This current study builds upon this past research in two very important ways.

1) Using LPA [30], we assessed health behaviors using a risk-taking framework. That is, we identified subtypes of individuals based on their propensity to engage in each health-related risk. Propensity, or inclination to engage in a health behavior, is a known predictor of engagement in the behavior. While LPA is a data-driven technique, based on previous research [29] we expected to identify a subtype of individuals characterized by higher propensity to engage in health benefiting behaviors (i.e., medical risks) and a simultaneous lower propensity to engage in health-harming behaviors (i.e., health/safety risks).

2) In addition to examining demographic factors related to membership in each subtype, we also assess the incremental role of the sociocultural factors described in the previous section (i.e., gender role orientation, individualism, collectivism, familism, GLHC). Due to noted gender differences in risk-taking [8], we further examined how gender moderated the relations between sociocultural factors and health-related risk-taking.

\section{Method \\ Participants and procedure}

The data were collected in November 2018 as part of a national study examining factors related to health and sickness behaviors among U.S. adults [31]. All procedures were approved by an Institutional Review Board (IRB), and all methods from this study were conducted in accordance with IRB guidelines. Questionnaires were administered by Qualtrics, a webbased survey platform. To be included, participants provided written informed consent, and: 1) were between 18 and 55 years old, 2) identified as nonHispanic White, African American, or Hispanic, and 3 ) experienced sickness at some point during the past year. Of the 2815 people invited to participate, 1261 met inclusion criteria and elected to complete the survey. 


\section{Measures}

\section{Health-related risk-taking}

Two subscales from the Domain Specific Risk-Taking (DOSPERT-M ${ }^{64}$ ) measured health-related risk-taking. Six items were from a medical risk-taking subscale (e.g., "taking daily medication ..." ; having "knee replacement surgery ..." ) and five items were from a health/safety risk-taking subscale (e.g., "drinking heavily ..."; "driving a car without a seatbelt"). Items were measured on a scale of 1 (extremely unlikely) to 7 (extremely likely). Internal consistency values were good (medical $\alpha=.78$; health/safety $\alpha=.83$ ).

\section{Demographic factors}

Participants reported age using an open-ended response. We measured education level (7-point scale; $1=$ some high school, 7 = doctorate); race/ethnicity $(1=$ non-Hispanic White, $2=$ African American, $3=$ Hispanic); annual income (12-point scale; $1=$ less than $\$ 10,000 ; 12=$ more than \$150,000); marital status ( $1=$ currently married, 2 = previously married [i.e., widowed/separated/divorced], 3 never married); and gender $(1=$ male, $2=$ female).

\section{Sociocultural factors}

Gender role orientation Means were calculated for six items [32] assessing the degree to which participants viewed their attitudes/beliefs, appearance, and interests as either masculine or feminine on a 7 -point scale $(1=$ very masculine, $7=$ very feminine). Internal consistency was excellent $(\alpha=.97)$.

Individualism and collectivism Means were calculated for six items measuring individualism (e.g., "Competition is the law of nature") and eight items measuring collectivism (e.g., "The well-being of my co-workers is important to me") using a 7-point scale [33] (1= strongly disagree, $7=$ strongly agree). Both subscales were internally consistent (individualism $\alpha=.82$; collectivism $\alpha=.85$ ).

Familism Ten items assessed familism [34] (e.g., "When it comes to social responsibility, blood really is thicker than water") with a 5 -point scale $(1=$ strongly disagree, $5=$ strongly agree) and were averaged for a total familism score. Internal consistency was excellent $(\alpha=.93)$.

God locus of health control (GLHC) The summed score of six items assessed the extent participants felt God controlled their health [26] (e.g., "Most things that affect my health happen because of God") using a 7point scale ( $1=$ strongly disagree, $7=$ strongly agree). Internal reliability was excellent $(\alpha=.95)$.

\section{Analytic strategy}

Post-stratification weights were applied to survey data based on U.S. census reports of race/ethnicity, sex, and income. A latent profile analysis (LPA) was conducted with Mplus version 8.4 with full information maximum likelihood estimation using the health/safety and medical risk-taking items from the DOSPERT-M as indicators. LPA has become an increasingly popular analytic technique to assess the associations of concurrent health behaviors [35], and is advantageous over other cluster analytic techniques (e.g., hierarchical clustering) because it is model-based, allowing for researchers to more objectively assess how well the selected model fits the data [30]. In LPA, participants are grouped according to similarities across categories of a latent variable. Each participant is classified as a member of a single category. Categories are identified using data-driven techniques and guided by theoretical conceptualizations and the principle of parsimony. The process of identifying the categories (i.e., class enumeration) is informed by multiple indices [30], and adjusted according to recommendations specific to working with complex survey data [36]. As complex survey weights were applied to the data, we were guided by changes in the Bayesian Information Criterion (BIC), which indicates the probable odds of one model when compared to another model [37]. Lower BIC values are interpreted as better. Entropy, an indication of overall classification precision, was also inspected. Entropy scores can range from 0 to 1; higher scores reflect better classification precision [38]. In addition to assessing overall model entropy, we examined univariate entropy across each of the latent profile indicators. Univariate entropy is a measure of how well individual indicators can identify the profiles gleaned during class enumeration. Scores range from 0 to 1 , with higher scores suggesting the indicator provides more information about the latent profiles than indicators with lower scores. This allowed us to further contextualize our profile selection [39]. Finally, interpretability, theoretical plausibility, and parsimony pertaining to the emergent latent categories also governed class enumeration decision-making.

Next, chi-square, ANOVA, and ANCOVA analyses assessed the demographic and sociocultural characteristics of profile members. ANOVA and ANCOVA analyses were interpreted using a Bonferroni adjusted $p$ value of $<.006$ to adjust for Type I error [40]. Dunnett $\mathrm{C}$ post-hoc pairwise comparisons were also conducted using a Bonferroni adjustment to account for unequal sample sizes across profile membership and violations of homogeneity of variance [41]. We then conducted follow-up a multinomial logistic regression to determine the incremental effects of demographic and sociocultural factors on group membership. 


\section{Results}

Sample weights were used when conducting all analyses. Two responses were omitted from the analysis for missing data necessary for computing sample weights (i.e., one case missing age data, the other missing sex data). See Table 1 for weighted descriptive statistics of the study's sample. A zero-order correlation analysis indicated that all sociocultural factors were positively associated $(p<.05)$, with the exception of gender role orientation and GLHC (n.s.).

\section{Latent profile analysis (LPA)}

Using BIC, entropy, and interpretability of profiles, a four-profile model was selected. See Table 2 for numeric class enumeration details. Specifying a five-profile solution yielded a warning that the best loglikelihood value could not be replicated, indicating five profiles were too many to extract from these data. Clear patterns of responses emerged across the four profiles (Fig. 1). While all subtypes were characterized by generally higher endorsements of medical risk-taking than health/safety related risk-taking, with few exceptions participants grouped themselves as low $(n=305,24.24 \%)$, moderate
Table $\mathbf{2} L P A$ enumeration indices

\begin{tabular}{lllll}
\hline & AIC & BIC & aBIC & Entropy \\
\hline 1 & $59,914.74$ & $60,027.78$ & $59,957.90$ & - \\
2 & $57,164.73$ & $57,339.42$ & $57,231.42$ & .94 \\
3 & $56,373.43$ & $56,609.78$ & $56,463.67$ & .82 \\
4 & $55,134.84$ & $55,432.85$ & $55,249.61$ & .89 \\
\hline
\end{tabular}

Note. AIC = Akaike's Information Criterion; BIC = Bayesian Information Criterion; $\mathrm{aBIC}=$ adjusted $\mathrm{BIC}$

( $n=235,18.63 \%)$, or high $(n=154,12.26 \%)$ propensity risk-takers. One profile emerged $(n=565,44.88 \%)$ that stood out from the other three, with a noticeably steeper difference across mean endorsements of medical indicators and health/safety indicators. Profiles were labeled 1) low propensity, 2) moderate propensity, 3) high propensity, 4) divergent. The highest univariate entropy score was .611 (item: propensity to drive without a seatbelt) and the lowest univariate entropy score was .182 (item: propensity to opt for general, rather than local anesthesia for a wisdom tooth extraction). The remaining indicators' univariate entropy scores fell between .201 and .260 .

Table 1 Weighted sample characteristics

\begin{tabular}{|c|c|c|c|c|c|}
\hline \multirow[t]{2}{*}{ Variable } & \multicolumn{5}{|c|}{ Frequency (Percent) } \\
\hline & Total Sample & Low Propensity & Moderate Propensity & High Propensity & Divergent Propensity \\
\hline \multicolumn{6}{|l|}{ Gender } \\
\hline Male & 423(33.6) & $83(26.9)$ & 98(37.9) & $63(39.7)$ & $178(33.6)$ \\
\hline Female & $836(66.4)$ & $227(73.1)$ & $161(62.1)$ & $96(60.3)$ & $351(66.4)$ \\
\hline \multicolumn{6}{|l|}{ Race/ethnicity } \\
\hline non-Latinx White & $856(68.0)$ & $208(67.2)$ & 173(66.6) & 124(77.4) & $351(66.4)$ \\
\hline Latinx & $229(18.20)$ & $55(17.7)$ & $49(18.9)$ & 18(11.1) & 108(20.3) \\
\hline Black/African American & $174(13.80)$ & $47(15.1)$ & $38(14.6)$ & $18(11.5)$ & $70(13.3)$ \\
\hline \multicolumn{6}{|l|}{ Marital Status } \\
\hline Married & $508(40.3)$ & $105(33.8)$ & $102(39.2)$ & $87(54.5)$ & $215(40.5)$ \\
\hline Formerly Married & $205(16.3)$ & $53(17.2)$ & $50(19.3)$ & $17(10.5)$ & $85(16.1)$ \\
\hline Never Married & $546(43.3)$ & $152(49.0)$ & 108(41.6) & $56(35.1)$ & $230(43.4)$ \\
\hline \multirow[t]{2}{*}{ Variable } & \multicolumn{5}{|c|}{ Mean (Standard Deviation) } \\
\hline & Total Sample & Low Propensity & Moderate Propensity & High Propensity & Divergent Propensity \\
\hline Age & $37.02(12.49)$ & $37.11(12.89)$ & $36.58(12.41)$ & $35.19(11.10)$ & $37.73(12.67)$ \\
\hline Income & $5.62(3.73)$ & $5.77(3.83)$ & $5.05(3.58)^{a}$ & $6.74(3.95)^{\mathrm{ab}}$ & $5.46(3.62)^{b}$ \\
\hline Education & $3.56(1.51)$ & $3.49(1.41)$ & $3.52(1.55)$ & $3.93(1.58)$ & $3.52(1.53)$ \\
\hline Gender role identity & $4.71(1.82)$ & $5.01(1.69)^{\mathrm{a}}$ & $4.51(2.01)$ & $5.00(1.77)$ & $4.55(1.79)^{a}$ \\
\hline Individualism & $5.82(1.72)$ & $5.74(1.58)$ & $5.59(1.89)$ & $6.26(1.97)$ & $5.86(1.60)$ \\
\hline Collectivism & $5.77(1.68)$ & $5.69(1.69)$ & $5.61(1.72)$ & $6.23(1.90)$ & $5.74(1.57)$ \\
\hline Familism & $3.83(.98)$ & $3.77(1.07)$ & $3.72(.95)$ & $3.84(1.18)$ & $3.91(.86)$ \\
\hline GLHC & 19.38(9.54) & $18.02(9.46)$ & $19.04(9.42)$ & 23.06(10.83) & $19.24(8.95)$ \\
\hline
\end{tabular}

Note. $N=1259$. Weighted data presented; variables with significant omnibus frequency or mean differences across latent profiles highlighted in bold; means and standard deviation are unadjusted (adjusted means reported in text); superscripts indicate significant pairwise comparisons along each row 


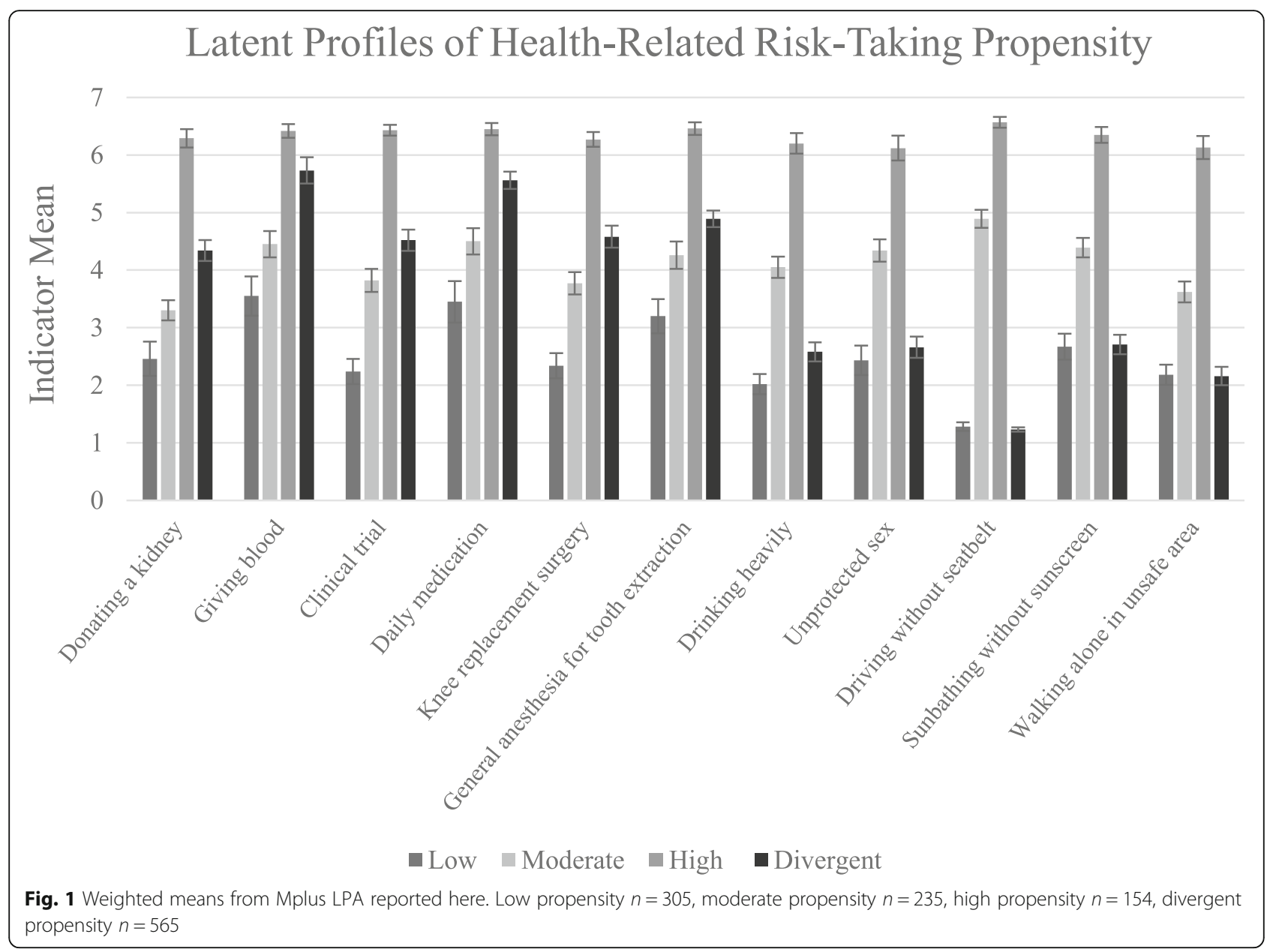

\section{Demographic analysis}

Chi-square analyses indicated that gender was related to profile membership $\left(\chi^{2}[N=1257,3]=11.15, p=.011\right.$; $\phi=.09)$. A higher proportion of women $(27.20 \%)$ than men (19.2\%) were low propensity profile members, while a higher proportion of men than women were members in both the moderate $($ men $=23.2 \%$; women $=$ $19.3 \%)$ and high $(\operatorname{men}=14.9 \%$; women $=11.5 \%)$ propensity profiles. Divergent profile membership was equivalent across men and women (approximately $42 \%$ each). Marital status was also related to profile membership $\left(\chi^{2}[N=1260,6]=20.86, p=.002 ; \phi=.13\right)$. Nearly identical proportions of individuals from each marital status group identified as divergent profile members (approximately $42 \%$ ), with proportional discrepancies occurring in both the low and high propensity profiles. For the low propensity profile there were fewer currently married $(20.6 \%)$ than formerly married $(25.9 \%)$ and never married $(27.8 \%)$ participants. For the high propensity profile, there were more married (17.1\%) than never married (10.3\%) and formerly married $(8.3 \%)$ participants. Race/ethnicity was unrelated to profile membership $(p=.142)$.
ANOVA analyses indicated the average age of participants did not differ across profiles, $(p=.234)$. Mean income was higher for members of the high $(M=7.01, S D=$ $3.80)$ and low $(M=6.03, S D=3.88)$ groups than for members of the moderate $(M=5.13, S D=3.65)$ group. Income was also higher in the high propensity profile than the divergent propensity profile $(M=5.59, S D=3.94), F(3$, $1254)=8.84, p<.001 ; \eta_{\mathrm{p}}{ }^{2}=.02$. Further, education level was significantly different across profiles, $F(3,1172)=4.16$, $p=.006$. Given the strong conceptual relation between income and education, we conducted a follow-up ANCOVA controlling for income, which rendered the effect of education level non-significant, $(p=.116)$.

\section{Sociocultural analysis}

Factorial ANCOVAs assessed the mean differences of each sociocultural factor in terms of profile membership. Each model included gender, marital status, and income, as well as each sociocultural factor not specified as the dependent variable as covariates to better assess the incremental and unique relations between profile memberships and the sociocultural factor of interest. We 
describe the main effects of both profile and gender, and the interaction effect between the two variables, below.

There was a difference in gender role orientation in terms of both profile $[F(3,1161)=5.17, p=.002$; $\left.\eta_{\mathrm{p}}{ }^{2}=.01\right]$ and gender $[F(1,1161)=466.77, p<.001$; $\left.\eta_{\mathrm{p}}{ }^{2}=.29\right]$. Low propensity profile members endorsed gender role orientation significantly higher (i.e., orienting toward femininity) than divergent profile members; no other pairwise differences were found. Women scored significantly higher than men on gender role orientation. The interaction between profile and gender was nonsignificant, $(p=.068)$.

There were no differences in individualism across propensity profiles $[F(3,1161)=1.90, p=.129]$. Men endorsed individualism more than women, $F(1,1161)=$ 39.32, $p<.001 ; \eta_{\mathrm{p}}{ }^{2}=.03$, although there was no interaction between profile and gender $(p=.304)$. Regarding collectivism, no differences were detected across propensity profiles $(p=.788)$, gender $(p=.213)$, or the interaction between the two variables $(p=.911)$.

For familism, the $F$ statistic for profile $(p=.014)$ and gender $(p=.040)$ did not pass the conservative corrective threshold of .006. The interaction between gender and profile was nonsignificant $(p=.437)$. GLHC differences across profiles approached significance $(p=.008)$, and men endorsed GLHC more than women, $F(1,1161)=12.77$, $\left.p<.001 ; \eta_{\mathrm{p}}^{2}=.01\right)$. However, the interaction between profile and gender was nonsignificant GLHC ( $p=.066)$.

\section{Follow-up multinomial regression}

Because the divergent profile showed a notable uncoupling of health/safety risk-taking items and medical risk- taking items, whereby the former was endorsed much less than the latter, we conducted a follow-up multinomial logistic regression to examine characteristics of divergent profile members compared to other profiles' members. For a detailed exploration, we included all demographic and sociocultural factors described earlier and set significance at $p<.050$.

Numeric results are in Table 3. Compared to low propensity profile membership, there was a greater probability for divergent profile members to 1 ) have lower income, 2) be married (relative to being never married), 3) orient toward masculinity, and 4) endorse more familism. Compared to moderate propensity profile membership, there was a greater probability for divergent profile members to endorse more individualism and familism. Compared to high propensity profile membership, there was a greater probability for divergent profile members to 1) be older, 2) be White, as compared to Hispanic, 3) orient toward masculinity, 4) endorse less GLHC, and 4) endorse more familism.

\section{Discussion \\ LPA findings}

For three profiles, responses appeared to map onto a general propensity for risk-taking (low, moderate, and high), particularly among the health/safety items. There were some notable similarities across profiles. For instance, across low, moderate, and divergent profiles, more invasive medical risk behaviors were generally endorsed lower than less obviously invasive medical risk behaviors. Moreover, the least endorsed invasive medical items were comprised of behaviors that potentially

Table 3 Coefficients from multinomial logistic regression model

\begin{tabular}{|c|c|c|c|c|c|c|c|c|c|c|c|c|}
\hline \multirow[b]{2}{*}{ Variable } & \multicolumn{4}{|c|}{ Low vs. Divergent Propensity } & \multicolumn{4}{|c|}{ Moderate vs. Divergent Propensity } & \multicolumn{4}{|c|}{ High vs. Divergent Propensity } \\
\hline & $B$ & $S E$ & $p$ & OR & $B$ & SE & $P$ & OR & $B$ & $S E$ & $p$ & OR \\
\hline Age & -.01 & .01 & .224 & & -.01 & .01 & .057 & & -.04 & .01 & $<.001$ & .97 \\
\hline Education & -.05 & .06 & .46 & & .06 & .07 & .373 & & .00 & .08 & .961 & \\
\hline Income & .07 & .03 & .011 & 1.07 & -.04 & .03 & .150 & & .04 & .04 & .273 & \\
\hline Married & -.27 & .19 & .048 & .69 & .17 & .20 & .397 & & .30 & .25 & .231 & \\
\hline Formerly Married & .01 & .23 & .970 & & .42 & .24 & .085 & & .09 & .34 & .803 & \\
\hline Gender (Male) & .16 & .22 & .468 & & .57 & .23 & .013 & & .34 & .26 & .190 & \\
\hline Latinx & -.15 & .21 & .459 & & -.11 & .21 & .619 & & -.79 & .30 & .008 & .453 \\
\hline African American & .20 & .22 & .377 & & .02 & .24 & .948 & & -.24 & .30 & .783 & \\
\hline Gender Role Orientation & .19 & .06 & .001 & 1.21 & .09 & .06 & .134 & & .18 & .07 & .009 & 1.19 \\
\hline Individualism & -.05 & .06 & .385 & & -.12 & .06 & .033 & .883 & .02 & .08 & .793 & \\
\hline Collectivism & .02 & 0.06 & .720 & & .07 & .07 & .320 & & .07 & .09 & .459 & \\
\hline Familism & -.20 & .08 & .019 & .821 & -.21 & .09 & .018 & .810 & -.35 & .11 & .001 & .71 \\
\hline God Locus of Health Control & -.01 & .01 & .174 & & .00 & .01 & .948 & & .03 & .01 & .009 & 1.03 \\
\hline
\end{tabular}

Note. $N=1259$. Weighted data presented. Divergent profile reference for all other profiles. Significant effects highlighted in bold. Exp(B) (odds ratio) presented for significant effects only. The reference group for married and formerly married is never married. The reference group for male is female

The reference group for both Hispanic and African American is non-Hispanic White. 
benefited others more than oneself (e.g., donating a kidney). There were similar trends across profiles for health/safety-related risks, particularly across the low and divergent propensity profiles, and both endorsed driving without a seatbelt the least. For these participants, perhaps the potential adverse consequences of driving without a seatbelt (e.g., serious injury) serve as a deterrent. There were additional similarities across the low and moderate profiles for kidney donation, blood donation, and participating in a clinical trial, which could arguably be perceived as entirely altruistic when compared to other Univariate scores suggested that the propensity to not wear a seatbelt was the strongest identifier of all of the profiles while the propensity to opt for general, rather than local anesthesia for a wisdom tooth extraction was the weakest individual identifier of the profiles. It is possible that this latter item's low univariate entropy score was due to a nuance in the wording of the item as compared to the other indicators. Specifically, this item asks participants to report their propensity to engage in a health-related risk behavior (i.e., choice of anesthesia) after another health-related risky decision has already been made (i.e., tooth extraction). Asparouhov and Muthén [39] indicate that items with scores that are nearing zero may be omitted from the model as they do not contribute substantial information about the characteristics of the profiles. We elected to retain this item in the interest of preserving all health-related indicators of the DOSPERT-M to better inform future researchers examining health-related risk-taking with this measure. Univariate entropy among the remaining indicators were modest. In the context of the relatively high model entropy, it is suggestive that the collection of items is more important for identifying profiles than singular indicators.

\section{Profile characteristics}

Results suggested being married was associated with generally high risk-taking while being never married was associated with generally low risk-taking. Research suggests marriage may serve as either a risk or protective factor across a range of health behaviors [42]. Married people may be more likely to have health insurance [42], which could contribute to a greater willingness to engage in health-related risk-taking. Other research suggests that married couples influence their spouses to limit behaviors that may compromise health [43], and that spousal health risk behaviors positively correlate with one another [44]. This may explain the current findings, though spousal risk-taking was not measured in this study. Also, high propensity profile members were more likely to have a higher income than moderate and divergent profile members. This is consistent with literature suggesting that individuals with higher incomes have more access to - and may be more likely to seek - medical care [45], and other literature connecting higher income levels with more engagement in some harmful health behaviors (e.g., hazardous alcohol use and related behaviors) [46]. With this in mind, it is possible that the potential adverse health consequences associated with some of health-related risks may be perceived as less of a hindrance for those who can afford medical care.

Aligned with theory that suggests health-risk behaviors may be part of an overarching gendered script [47], men were more likely than women to be members of higher health/safety risk profiles. Similarly, orienting toward femininity related to a higher probability of being a generally low risk-taker. Previous research suggests that men view potential health-related hazards as substantially less risky and are more inclined to participate in health-related risk activities than women [48]. Risktaking has been described as part of a hegemonic masculine gender role that is prevalent in Western societies and a potential source of status among other men [49]. Connell \& Messerschmidt [49] note that gender is a relative construct; thus, it is also possible that refraining from risk-taking may be viewed as part of a feminine gender role, as suggested in previous research [50].

\section{Factors predicting divergent profile membership}

The divergent profile exhibited the clearest differentiation between lower endorsements of health/safety-related risk-taking and higher endorsements of medicalrelated risk-taking. Data showed married participants were more likely to be divergent, rather than low, propensity profile members compared to never married participants. As expected from research that suggests risktaking declines with age [8], older participants were more likely than younger participants to be members of the divergent profile than the high-risk profile. It is possible that older adults in our sample perceived medical care more favourably than younger adults [51]. In addition, Hispanics were more likely than non-Hispanic Whites to be members of the divergent rather than the high propensity profile, aligning with research indicating that Hispanics view potentially hazardous health behaviors as more risky than non-Hispanic Whites [48].

One seemingly counterintuitive finding suggested divergent profile members had lower incomes than low propensity profile members, indicating that lower income predicted higher medical risk-taking. It is possible this connection may be a function of uncertain future environments. That is, individuals in unpredictable or harsh environments (e.g., lower socioeconomic circumstances [52]) may gravitate toward risky behaviors, particularly those with immediate benefits and future costs [53]. Medical risk-taking may fit this pattern. For 
example, present relief from allergy symptoms may outweigh future costs of long-term antihistamine use.

Consistent with the ANCOVA findings, femininity was related to low, rather than divergent, profile membership; however, results also showed that femininity was related to high, rather than divergent, profile membership, and contrasts gender role theories previously described. It is feasible that this is a limitation of measurement. Participants in this study rated themselves along a continuum as masculine or feminine. The extant gender role research highlights the complex and multidimensional nature of gender roles, and the importance of accounting for these nuances when predicting health behaviors [54].

Surprisingly, individualism but not collectivism predicted divergent profile membership. Individualisticoriented individuals were more likely to engage in medical risk-taking but less likely to engage in health/safety risk-taking than people who generally endorse moderate levels of risk-taking. Theory suggests individualistic people prioritize personal goals and responsibilities [55]. Our findings indicate that the inclinations to refrain from potentially harmful health behaviors while also engaging in potentially beneficial health behaviors may be an enactment of individualistic values, perhaps as a means of self-preservation. The null effects of collectivism were unexpected, given research linking collectivism to health behaviors [6]. As measured in this study [33], collectivism captured participants' values related to several groups (e.g., family, co-workers), which may have contributed to the lack of collectivism-related findings in these results. If the group that a person feels connected to informs their perceptions of risk-taking, more specificity about the group may be needed.

Importantly, familism predicted membership in the divergent profile compared to all other profiles. Like collectivism, familism emphasizes interdependence [34], though exclusively in relation to family. Previous research links familism to better physical and subjective health [56, 57], and to less engagement in health/safety risk behaviors [22]. As many of the health/safety related risks may be perceived as more hazardous than many of the medical risks, familism-oriented individuals might be more likely to engage in medical, but not health/safety, risk-taking. Researchers have also linked familism to prosocial tendencies to help others [58], which may contribute to the willingness to engage in medical risks that do not directly preserve the self (e.g., kidney donation).

Finally, lower GLHC was related to membership in the divergent profile as compared to the high-risk profile. Some research suggests that assigning control of one's health to an outside source reduces one's ability to accurately perceive risk [59]. Additionally, research indicates that people who assign locus of control to an external source may not be inclined to seek out riskrelated information [60]. In this case, not having as much information about the potential adverse effects of engaging in health-related risk-taking may render people with higher GHLC more comfortable with such risks.

\section{Strengths, limitations, and future directions}

This study must be interpreted considering some limitations. Data were cross-sectional and cannot address directionality. In addition, the non-convergence of the LPA solution with five profiles may reflect insufficient data points to support five subtypes and does not necessarily indicate that five or more profiles do not exist. Examining this study's research questions with larger samples would be beneficial to assess the veracity of this potential limitation.

Criteria for the larger project from which these data are derived required that participants reported experiencing an illness in the past year, although there were no restrictions on illness severity. Although adults in the U.S. experience an average of two to three colds annually [61], these findings may not generalize to those individuals who had not been sick during the previous year. Relatedly, we did not account for individual health of participants or the health-related behaviors they currently engaged in (e.g., current medications), although these factors may influence how likely they are to endorse some of the health variables measured in this study. Also, the effect sizes reported in this study were generally modest and suggest that future research should model sociocultural factors as upstream of more proximal mechanisms to risk-taking within a more comprehensive framework. For instance, researchers could use a mixed methods approach to identify the reasons that individuals find these health behaviors risky (e.g., what consequences do they anticipate), and then link these factors to those risk perceptions. Furthermore, in the interest of having a large enough sample to analyze differences in health outcomes across race and ethnicity, we only included U.S. adults who identified as either White, Black, or Hispanic, which limits the ability of this study to generalize to U.S. adults from other racial and ethnic backgrounds. Also, though analyzing gender as both a label (i.e., male/female) and as an orientation (i.e., masculine/feminine) was a strength of the study, a binary perspective on gender does not adequately address the complex gender identities experienced by people in many parts of the world.

Although it is beyond the scope of the current study to examine how the link between sociocultural values and health-related risk-taking profiles varied as a function of multiple key demographic factors, there is a strong practical and theoretical rationale for doing so. For example, older adults' perspectives are shaped by 
experiences and cognitive functioning that is markedly different than those of younger adults [62]. While the current study found links between age and risk-taking propensity that mapped onto past research, future research that examines how age moderates the relationship between the independent and dependent variables of interest in this study be of even further benefit for increasingly targeted public health programming.

\section{Conclusion}

Electing to engage in any health behavior, whether the behavior is medically recommended or not, is characterized by risk. The decision to engage in specific health behaviors then depends upon, among other things, individuals' assessments of the potential consequences of the behavior. These assessments include both the probabilities and the valence of the respective consequences. For health-related risk behaviors such as donating blood, a person may weigh the possibility of physical discomfort of the needle against the possibility of experiencing psychological satisfaction from assisting someone in need. For health-related risk behaviors such as heavy alcohol use, a person may weigh the possibility of long-term cirrhosis of the liver against the possibility of short-term relief from stress. Perceptions of the consequences associated with each health behavior thus play a major role in shaping the willingness of a person to engage in health-related risk-taking.

By examining health-related risk-taking propensity across both medical risks and health/safety risks using a person-centered approach, this study aligns with previous research suggesting that there are subtypes of individuals who can be considered "health-promoting." [29] Whereas previous research has found these healthpromoting subtypes in regards to frequency of specific types of health behavior [29], this current study suggests that similar groups of people can also be identified by their propensity to engage in such behaviors. It is important to consider that the context that underlies the decision to engage in the risk behavior at the moment of the behavior is unique [1] (e.g., the careful and longterm planning of an extensive medical procedure as compared to the decision to have sexual intercourse without a condom). We cannot know the extent to which the propensity that individuals in this study are endorsing map onto their current or later behavior. However, an individual's assessment of their own inclination to engage in each of these behaviors may be shaped by common upstream factors, and there is supporting research that indicates this inclination may predict later actual engagement in the behavior [63]. As a novel contribution to the literature, this current study shed light on the sociocultural values that individuals who are likely to engage in health benefiting behaviors ascribe to, above and beyond more often studied demographic characteristics. In the interest of both public and personal health, it is imperative that health experts understand potentially modifiable characteristics that may shape peoples' inclinations to engage in health behaviors that benefit themselves and others, as well as inclinations to refrain from health behaviors that are generally hazardous. This study demonstrated that a subtype of people meeting this specific pattern of health protection can be identified. As such, this study is an important step toward refining health programs and materials designed to protect and improve personal and public health.

\section{Acknowledgments}

Not applicable.

\section{Authors' contributions}

Dr. Jessica Perrotte conceptualized the project, conducted all analyses, and wrote the first draft of the manuscript. Dr. Eric Shattuck provided substantive comments and revisions of Dr. Perrotte's initial and subsequent drafts. Mr. Colton Daniels and Dr. Xiaohe Xu provided additional comments and revisions to later drafts. Dr. Thankam Sunil is the PI on the overarching project from which these data are derived. All authors read and approved the final manuscript.

\section{Funding}

Funds to incentivize participants for the current study were procured by an internal grant from the University of Texas at San Antnomio (UTSA).

Availability of data and materials

The datasets used during the current study are available from the corresponding author on reasonable request.

\section{Declarations}

Ethics approval and consent to participate

All study procedures were approved by the Institutional Review Board at UTSA (IRB \#19-020E) and the study was conducted in accordance with IRB guidelines. Participants gave informed consent before beginning the study.

Consent for publication

Not applicable.

\section{Competing interests}

The authors declare they have no competing interests.

\section{Author details}

${ }^{1}$ Department of Psychology, Texas State University, UAC 253, 601 University Drive, San Marcos, TX 78666, USA. ${ }^{2}$ Institute for Health Disparities Research, University of Texas at San Antonio, One University Circle, MS 3.02.49, San Antonio, TX 78249, USA. ${ }^{3}$ Department of Public Health, The University of Tennessee at Knoxville, 335 Claxton Complex, 1122 Volunteer Boulevard, Knoxville, TN 37996, USA. ${ }^{4}$ Department of Sociology, University of Texas at San Antonio, One University Circle, San Antonio, TX 78249, USA. ${ }^{5}$ School of Public Administration, Sichuan University, No.24 South Section I, Yihuan Road, Chengdu 610065, China.

Received: 13 November 2020 Accepted: 10 March 2021

Published online: 19 March 2021

\section{References}

1. Figner B, Weber EU. Who takes risks when and why? Determinants of risk taking. Curr Dir Psychol Sci. 2011;20(4):211-6. https://doi.org/10.1177/0963 721411415790 . 
2. Vanzile-Tamsen C, Testa M, Harlow LL, Livingstong JA. A measurement model of women's behavioral risk taking. Health Psychol. 2006;25(2):249-54 https://doi.org/10.1037/0278-6133.25.2.249.

3. Hingson R, Zha W, Smyth D. Magnitude and trends in heavy episodic drinking, alcohol-impaired driving, and alcohol-related mortality and overdose hospitalizations among emerging adults of college ages 18-24 in the United States, 1998-2014. J Stud Alcohol Drugs. 2017;78(4):540-8. https://doi.org/10.15288/jsad.2017.78.540.

4. DiMatteo MR. Variations in patients' adherence to medical recommendations: a quantitative review of 50 years of research. Med Care 2004:42(3):200-9. https://doi.org/10.1097/01.mlr.0000114908.90348.f9.

5. Triandis HC. Collectivism v. individualism: a reconceptualization of a basic concept in cross-cultural social psychology. In: Verma GK, Bagley C. Bagley, editors. Cross-cultural studies of personality, attitudes, and cognition. MacMillan Press; 1988.

6. Schwartz SJ, Weisskirch RS, Zamboanga BL, Castillo LB, Ham LS, Park HQ, Donovan R, Kim SY, Vernon M, Davis MJ, Cano MA. Dimensions of acculturation: associations with health risk behaviors among college students from immigrant families. J Couns Psychol. 2011;58(1):27-41. https://doi.org/10.1037/a0021356.

7. Weber EU, Johnson EJ. Decisions under uncertainty: psychological, economic, and neuroeconomic explanations of risk preference. In Glimcher PW, Camerer CF, Fehr E, Poldrack RA, editors. Neuroeconomics: Decision Making and the Brain. Elsevier; 2009.

8. Josef AK, Richter D, Samanez-Larkin GR, Wagner GG, Hertwig R, Mata R. Stability and change in risk-taking propensity across the adult life span. J Pers Soc Psychol. 2016;111(3):430-50. https://doi.org/10.1037/pspp0000090.

9. Onge JM, Krueger PM. Health lifestyle behaviors among U.S. adults. 2017. SSM Pop Health; 3:89-98.

10. Hanoch Y, Rolison JJ, Freund AM. Does medical risk perception and risk taking change with age? Risk Anal. 2018;38(5):917-23. https://doi.org/10.1111/risa.12692.

11. Courtenay W. Constructions of masculinity and their influence on men's well-being: a theory of gender and health. Soc Sci Med. 2000;50(10):1385401. https://doi.org/10.1016/S0277-9536(99)00390-1.

12. Gast J, Peak T. "It used to be that if it weren't broken and bleeding profusely, I would never go to the doctor": men, masculinity, and health. Am J Mens Health. 2010;5:318-31.

13. Wood W, Eagly AH. Two traditions of research on gender identity. Sex Roles. 2015;73(11-12):461-73. https://doi.org/10.1007/s11199-015-0480-2.

14. Wang XT, Zheng R, Xuan YH, Chen J, Li S. Not all risks are created equal: a twin study and meta-analyses of risk-taking across seven domains. J Exp Psychol: Gen. 2016;145(11):1548-60. https://doi.org/10.1037/xge0000225.

15. Kuhn DK. How do people know? Psych Sci. 2001;12(1):1-8. https://doi.org/1 0.1111/1467-9280.00302.

16. Bardi A, Schwartz SH. Values and behavior: strength and structure of relations. Personal Soc Psychol Bull. 2003;29(10):1207-20. https://doi.org/1 $0.1177 / 0146167203254602$.

17. Kim HS, Sherman DK, Updegraff JA. Fear of Ebola: the influence of collectivism on xenophobic threat responses. Psychol Sci. 2016;27(7):935-44 https://doi.org/10.1177/0956797616642596.

18. Triandis HC. Individualism \& Collectivism. 2018. Routledge Taylor \& Francis Group.

19. Shenga N, Pal R, Sengupta S, Pal S. Correlates of voluntary blood donation among people in a hill capital in India. Int J Green Pharm. 2009;3:167-74.

20. Sabogal F, Marín G, Otero-Sabogal R. Hispanic familism and acculturation: what changes and what doesn't? Hisp J Beh Sci. 1987;9(4):397-412. https:// doi.org/10.1177/07399863870094003.

21. Schwartz SJ. The applicability of familism to diverse ethnic groups: a preliminary study. J Soc Psychol. 2007;147(2):101-18. https://doi.org/10.3200/ SOCP.147.2.101-118

22. Dillon FR, De La Rosa M, Sastre F, Ibañez G. Alcohol misuse among recent Latino immigrants: the protective role of preimmigration familismo. Psychol Add Beh. 2013;27(4):956-65. https://doi.org/10.1037/a0031091.

23. Schwartz SJ, Weisskirch RS, Hurley EA, Zamboanga BL, Park IJ, Su Yeong K, Umaña-Taylor A, Castillo LG, Brown E, Greene AD. Communalism, familism and filial piety: are they birds of a collectivistic feather? Cultur Divers Ethnic Minor Psychol. 2010;16(4):548-60. https://doi.org/10.1037/a0021370.

24. Pew Research Center. Belief in God. U.S. Religious Landscape Study. 2014. https://www.pewforum.org/religious-landscape-study/belief-in-god/

25. Boyd JM, Wilcox S. Examining the relationship between health locus of control and god locus of health control: is god an internal or external source? J Health Psychol. 2020;25(7):931-40. https://doi.org/10.1177/13591 05317739099

26. Wallston KA, Malcarne VL, Flores L, Handottir I, Smith CA, Stein MJ, Weisman $\mathrm{MH}$, Clements PJ. Does god determine your health? The God Locus Health Control Scale. 1999;23:131-42.

27. Debnam KJ, Holt CL, Clark EM, Roth DL, Foushee HR, Crowther M, Fouad M, Southward PL. Spiritual health locus of control and health behaviors in African Americans. Amer J Health Behav. 2012;36:360-72.

28. Ward J, Raude J. Understanding influenza vaccination behaviors: a comprehensive sociocultural framework. Expert Rev Vaccines. 2014;13(1):1729. https://doi.org/10.1586/14760584.2014.863156.

29. Saint Onge JM, Krueger PM. Health lifestyle behaviors among U.S. adults. 2017. SSM - Pop Health; 3:89-98.

30. Nylund-Gibson K, Choi AY. Ten frequently asked questions about latent class analysis. Transl Issues Psychol Sci. 2018;4(4):440-61. https://doi.org/10.1 037/tps0000176

31. Shattuck EC, Perrotte JK, Daniels CL, Xu X, Sunil TS. The contribution of sociocultural factors in shaping self-reported sickness behavior. 2020;14:4. https://doi.org/10.3389/fnbeh.2020.00004.

32. Kachen S, Steffens MC, Niedlich C. Traditional masculinity and femininity: Validation of a new scale assessing gender roles. 2016. Front Psychol; 7:956.

33. Sivadas E, Bruvold NT, Nelson MR. A reduced version of the horizontal and vertical individualism and collectivism scale: a four-country assessment. J Bus Res. 2008;61(3):201-10. https://doi.org/10.1016/j.jbusres.2007.06.016.

34. Gaines SO, Marelich WD, Blesdoe KL, Steers WN, Henderson MC, Granrose CS, Garcia BF, Farris KR, Page MS. Links between race ethnicity and cultural values as mediated by racial ethnic identity and moderated by gender. J Pers Soc Psychol. 1997;72(6):1460-76. https://doi.org/10.1037/0022-3514.72.6.1460.

35. McAloney K, Graham H, Law C, Platt L. A scoping review of statistical approaches to the analysis of multiple health-related behaviours. Prev Med. 2013;56(6):365-71. https://doi.org/10.1016/j.ypmed.2013.03.002.

36. Asparouhov T, Muthén B. (Using Mplus TECH11 and TECH14 to test the number of latent classes. Mplus Web Notes: No. 14. 2012. https://www.sta tmodel.com/examples/webnotes/webnote14.pdf

37. Vrieze SI. Model selection and psychological theory: a discussion of the differences between the Akaike information criterion (AIC) and the Bayesian information criterion (BIC). Psychol Methods. 2012;17(2):228-43. https://doi. org/10.1037/a0027127.

38. Gilles C, Soromenho G. An entropy criterion for assessing number of classes in a mixture model. J Classif. 1996;13:195-212.

39. Asparouhov T, Muthén B. Variable-specific entropy contribution. 2018. Available at: https://www.statmodel.com/download/UnivariateEntropy.pdf

40. Jaccard J, Guilamo-Raos V. Analysis of variance frameworks in clinical child and adolescent psychology: issues and recommendations. J Clin Child Adolesc Psychol. 2002;31(1):130-46. https://doi.org/10.1207/S15374424 JCCP3101_15.

41. Dunnett CW. Pairwise multiple comparisons in the unequal variance case. J Amer Stat Assoc; 1980;75(375):796-800. https://doi.org/10.1080/01621459.1 980.10477552

42. Wood RG, Goesling B, Avellar S. The effects of marriage on health: A synthesis of recent research evidence. 2007. Policy Res, Inc

43. Tucker JS, Anders SL. Social control of health behaviors in marriage. J Appl Soc Psychol. 2001;31(3):467-85. https://doi.org/10.1111/j.1559-1816.2001. tb02051.x.

44. Jeong S, Cho S. Concordance in the health behaviors of couple by age: a cross-sectional study. J Prevent Med Pub Health. 2018;51(1):6-14. https://doi. org/10.3961/jpmph.17.137.

45. Jacobs P, Rapoport J. The economics of health and medical care. Fifth edition. 2002. Jones and Bartlett Publishers.

46. Keyes KM, Hasin DS. Socio-economic status and problem alcohol use: the positive relationship between income and the DSM-IV alcohol abuse diagnosis. Addiction. 2008;103(7):1120-30. https://doi.org/10.1111/j.13600443.2008.02218.x

47. Courtenay WH. Constructions of masculinity and their influence on men's well-being: a theory of gender and health. Soc Sci Med. 2000;50(10):1385481. https://doi.org/10.1016/S0277-9536(99)00390-1.

48. Finucane ML, Slovic P, Mertz CK, Flynn J, Satterfield TA. Gender, race, and perceived risk: The 'white male' effect. Health Risk Soc. 2000:2:159-72.

49. Connell RW, Messerschmidt JW. Hegemonic masculinity: rethinking the concept. Gender Soc. 2005;19(6):829-59. https://doi.org/10.1177/08912432 05278639 . 
50. Perrotte JK, Martin JL, Piña-Watson B. Traditional feminine gender roles, alcohol use, and protective behavioral strategies among Latina college students. 2020. J Amer Coll Health; 1-9.

51. Campbell JL, Ramsay J, Green J. Age, gender, socioeconomic, and ethnic differences in patients' assessments of primary health care. Qual Health Care. 2001;10(2):90-5. https://doi.org/10.1136/qhc.10.2.90.

52. Belsky J, Schlomer GL, Ellis BJ. Beyond cumulative risk: distinguishing harshness and unpredictability as determinants of parenting and early life history strategy. Dev Psychol. 2012;48(3):662-73. https://doi.org/10.1037/a 0024454.

53. Hill EM, Ross $L T$, Low BS. The role of future unpredictability in human risktaking. Hum Nat. 1997;8(4):287-325. https://doi.org/10.1007/BF02913037.

54. Kaya A, Iwamoto DK, Grivel M, Clinton L, Brady J. The role of feminine and masculine norms in college women's alcohol use. Psychol Men Masc; 2016(2):17:206-214. https://doi.org/10.1037/men0000017.

55. Oyserman D, Coon HM, Kemmelmeier M. Rethinking individualism and collectivism: evaluation of theoretical assumptions and meta-analyses. Psychol Bull. 2002;128(1):3-72. https://doi.org/10.1037/0033-2909.128.1.3.

56. Corona K, Campos B, Chen C. Familism is associated with psychological well-being and physical health: main effects and stress-buffering effects. Hisp J Behav Sci. 2017;39(1):46-65. https://doi.org/10.1177/07399863166712 97.

57. Sayegh P, Knight BG. The effects of familism and cultural justification on the mental and physical health of family caregivers. J Geront Psychol Sci. 2010; 66B:3-14.

58. Knight GP, Mazza GL, Carlo G. Trajectories of familism values and the prosocial tendencies of Mexican American adolescents. Dev Psychol. 2018; 54(2):378-84. https://doi.org/10.1037/dev0000436.

59. Frijling BD, Lobo CM, Keus IM., Jenks KM, Akkermans RP, Hulscher ME, .. Grol, R. P. Perceptions of cardiovascular risk among patients with hypertension or diabetes. 2004. Patient Educ Couns; 52:47-53.

60. Cavaiola AA, Strohmetz DB. Perceptions of risk for subsequent drinking and driving related offenses and locus of control among first-time DUI offenders. Alcohol Treat Q. 2010;28(1):52-62. https://doi.org/10.1080/0734 7320903436169

61. Turner RB. The common cold. In: Bennet JE, Dolin R, Blaser MJ, eds. Mandell, Douglas, and Bennet's Principles and Practice of Infectious Diseases. 8th edition. W.B. Saunders; 2014:748-752.

62. Hartshorne JK, Germine LT. When does cognitive functioning peak? The asynchronous rise and fall of different cognitive abilities across the lifespan. Psychol Sci. 2015;26(4):433-43. https://doi.org/10.1177/0956797614567339.

63. Szrek H, Chao L, Ramlagan S, Peltzer K. Predicting (un) healthy behavior: a comparison of risk-taking propensity measures. Judgm Decis Mak. 2012;7(6): 716-27.

64. Butler S, Rosman A, Seleski S, Garcia M, Lee S, Barnes J, Schwartz A. A medical risk attitude subscale for DOSPERT. Judgm Decis Mak. 2012;7:18995

\section{Publisher's Note}

Springer Nature remains neutral with regard to jurisdictional claims in published maps and institutional affiliations.

Ready to submit your research? Choose BMC and benefit from:

- fast, convenient online submission

- thorough peer review by experienced researchers in your field

- rapid publication on acceptance

- support for research data, including large and complex data types

- gold Open Access which fosters wider collaboration and increased citations

- maximum visibility for your research: over $100 \mathrm{M}$ website views per year

At BMC, research is always in progress.

Learn more biomedcentral.com/submissions 